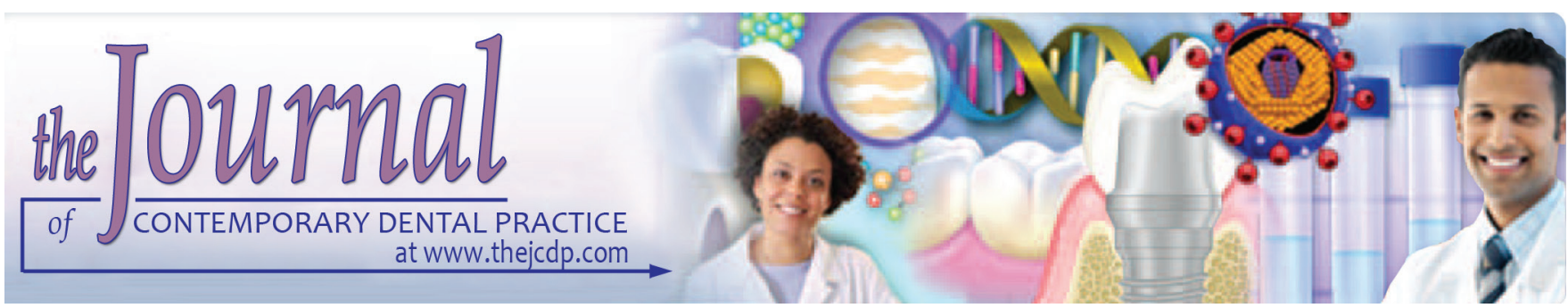

\title{
Determinants of Support for a Smoke-free University Policy
}

Mohamed Bamashmous

\begin{abstract}
Introduction: Health care professionals have an essential role in tobacco control through supporting tobacco control policy actions by promoting smoke-free workplaces and extending tobacco cessation programs.
\end{abstract}

Objective: To assess determinants of support for a smoke-free university policy among dental students.

Materials and methods: A cross-sectional study of dental students was carried out. Multiple linear regression analyses assessed the determinants of support for a smoke-free policy at the university.

Results: A total of 313 students completed the questionnaires. The multivariate model showed a direct relationship of support for a smoke-free university policy with being a nonsmoker $[\beta=1.95,95 \%$ confidence interval $(C l)=1.37-2.52, p<0.0001]$ and having greater knowledge of smoking health hazards ( $\beta=0.26,95 \% \mathrm{Cl}=0.20-0.30, p<0.0001)$. We detected an inverse relationship with being a man $(\beta=-0.49,95 \% \mathrm{Cl}=$ -2.73 to $-0.58, p=0.03$ ) and with increased willingness to accept second-hand smoke (SHS) exposure score $(\beta=-0.02$, $95 \% \mathrm{Cl}=-0.04$ to $-0.01, \mathrm{p}<0.0001)$.

Conclusion: This study found that a policy banning smoking would have support from those students who have knowledge of smoking health hazards and those unwilling to accept exposure to SHS.

Keywords: Second-hand smoke exposure, Smoke-free policy, Tobacco control, Universities.

How to cite this article: Bamashmous M. Determinants of Support for a Smoke-free University Policy. J Contemp Dent Pract 2018;19(7):799-807.

Source of support: Nil

Conflict of interest: None

Department of Dental Public Health, Faculty of Dentistry, King Abdulaziz University, Jeddah, Kingdom of Saudi Arabia

Corresponding Author: Mohamed Bamashmous, Department of Dental Public Health, Faculty of Dentistry, King Abdulaziz University, Jeddah, Kingdom of Saudi Arabia, e-mail: mbamashmous@kau.edu.sa

\section{INTRODUCTION}

Health care professionals have an essential role in tobacco control through educating their patients about the health hazards of tobacco use and supporting tobacco control policy actions by promoting smoke-free workplaces and extending the availability of tobacco cessation programs. ${ }^{1,2}$ Dentists can increase the awareness of women about the dangers of tobacco use during pregnancy and influence children and adolescents to follow a tobaccofree lifestyle. ${ }^{3}$ Also, patients perceived that their dentists had a vital role in smoking cessation activities and smokers were also more likely to stop smoking when suggested by their dentist. ${ }^{4}$

Physicians are aware of the health hazards associated with smoking and SHS exposure. Nevertheless, high numbers of physicians smoke and are exposed to SHS. $^{5-7}$ Smoking prevalence rates range from $5 \%$ to more than $40 \%$ among third-year medical and dental students across different countries. ${ }^{8-10}$ Also, about $70 \%$ of students reported SHS exposure in public places. ${ }^{8,9} \mathrm{In}$ Saudi Arabia, smoking prevalence among male medical students in two different universities in Riyadh was 13 and $24 \%$ respectively. ${ }^{11,12}$ In addition, $38 \%$ were exposed to SHS. ${ }^{11}$

Prevalence rates in the western region even are higher than in other regions of the country. ${ }^{13}$ One study revealed that $25 \%$ of male medical students attending King Abdulaziz University (KAU) in Jeddah, were current tobacco users. ${ }^{14}$ A cross-sectional study conducted among 336 Saudi dental students studying at KAU showed that the overall prevalence of smoking is $25 \%$ and nearly $50 \%$ of smokers started smoking during the dental program; ${ }^{10} 40 \%$ of male dental students are smokers, ${ }^{10}$ which is remarkably higher than the smoking prevalence rate among the general population (12-15\%) in Saudi Arabia. ${ }^{15-17}$ In addition, $96 \%$ of students are exposed to SHS in public places, such as cafés, restaurants, and universities. ${ }^{10}$ This is a significant problem, as it is higher than what was reported in many population-based studies. ${ }^{16-18}$ 
This makes dental students have special interest in smoking studies due to their higher exposure despite their education and role in tobacco control.

Saudi Arabia adopted smoke-free policies in public places in line with the World Health Organization Framework Convention on Tobacco Control which the country signed in 2005 and banned tobacco use in public places, such as airports, restaurants, and health care institutes. ${ }^{19}$ The highest level of achievement was attained in 2012. In addition, the advisory board of deans at KAU approved the smoking-free university project to protect its community from the harm of SHS exposure since April, 2004. ${ }^{20}$

Although a smoke-free policy was established, it is not effectively enforced. In a cross-sectional study published in 2017, 39\% of 336 dental students at KAU reported exposure to SHS at the university. ${ }^{10}$ This might be due to the fact that public tobacco use is not well addressed in the dental college curriculum. ${ }^{21}$ Health sciences university students in Barcelona supported indoor smokefree policies, but their support for extending smoke-free regulations to outdoor areas of university campuses was limited. ${ }^{22}$ It is necessary to educate students about tobacco control and emphasize their importance as role models before extending outdoor smoke-free legislation at university campuses. ${ }^{22}$ The community support for the smoke-free policy is an essential factor for the success of enforcing this policy. ${ }^{23}$

Comprehensive smoke-free policies are effectual in diminishing exposure to SHS and intention to smoke on University campus. ${ }^{24}$ A Russian study concluded that smoke-free universities help young adults avoid initiating regular smoking. ${ }^{25} \mathrm{~A}$ Vietnamese study reported that positive changes in knowledge and attitude toward smoke-free universities were associated with the adoption of tobacco control legislation. ${ }^{26}$ Several studies have investigated the attitudes toward a smoke-free policy in different countries. ${ }^{22,26-28}$ However, further work is needed to identify those factors critical for the support for a smoke-free policy to ensure the compliance with such policies..$^{22,26-28}$ Therefore, here, we evaluated factors affecting the support for a smoke-free university policy among dental students.

The objectives of the current study were:

- To evaluate the awareness and the compliance with the smoke-free university policy.

- To assess and identify factors affecting the support for a smoke-free university policy.

\section{MATERIALS AND METHODS}

This is a cross-sectional survey of dental students in Jeddah, Saudi Arabia. The study was conducted in accordance with the Declaration of Helsinki. Ethical approval was obtained from the ethical research committee at the Faculty of Dentistry at KAU (Approval No. 012-12).

\section{Participants and Recruitment}

We recruited dental students in person from the Faculty of Dentistry at KAU, which is the largest and oldest university in the western region. The undergraduate dental program at KAU is a 6-year program followed by a mandatory internship year. The actual clinical component of the training begins in the fourth year. We invited all senior students (4th, 5th, and 6th year and interns) studying at KAU to participate in this study $(n=380)$. We distributed an anonymous self-administered paper-based questionnaire with a cover letter explaining the aim of the study, the researchers' affiliation and contact information, and the voluntary nature of participation. Students were asked to compile all questionnaires together via one student and then return them to the investigator. Only completed questionnaires were used for the study. Respondents gave consent to be included by completing the questionnaire.

\section{Questionnaire}

The survey questionnaire consists of 30 questions, including closed-ended, multiple-response, and rating questions. Questions using a Likert scale that consisted of a 5-point scale, ranging from "strongly agree" to "strongly disagree." The questions were adapted from the literature. The questionnaire was evaluated by four health care professionals who are experts in the field for face and content validity. In addition, it was pretested before the final study to confirm that the questions were clear.

The questionnaire was structured in six sections. Section A surveyed the smoking status and smoking habit at the university (frequency and location of smoking at the university each day). Section B surveyed the exposure to SHS at the university (frequency of exposure to SHS, the frequency of smelling tobacco smoke and frequency seeing cigarette filters on the ground). Section C surveyed students' support for the smoke-free policy. Section D surveyed the students' awareness of the existence and implementation of the policy at the university. Section E addressed the demographics of the respondents.

At the beginning of the questionnaire, we informed participants that smoking refers to any type of tobacco, such as cigarettes, moassel, shisha, cigar, pipe, or any other form of tobacco. We categorized smoking as current smoker, former smoker, or nonsmoker which were defined as individuals who reported smoking any tobacco product currently, smoking any tobacco product in the 
past but not currently, and never smoked before respectively. The presence of a smoker in a household, friend's house, and exposure at the university were measured using a Yes/No question.

Knowledge of smoking hazards items were adapted from Mansour ${ }^{10}$ and Gharaibeh et al..$^{29}$ This part consisted of five statements: (1) tobacco smoke is dangerous for nonsmokers' health; (2) exposure to tobacco smoke can cause lung cancer in nonsmokers; (3) smoke from other people's cigarettes will shorten my life; (4) children who are exposed to tobacco smoke have more illnesses, such as colds; and (5) parents or adults should not smoke near children. Respondents rated these five items using a 5 -point Likert scale as follows: strongly agree $=5$; agree $=4$; neutral $=3$; disagree $=2$; and strongly disagree $=1$.

The willingness to accept SHS exposure-a multicomponent 13-item scale with an internal consistency of 0.87-was developed by Mansour and Bakhsh. ${ }^{30}$ The scale allows the calculation of a total score. ${ }^{30}$ The support for a smoke-free policy was measured using the following three statements: (1) a university should be a smoke-free environment; (2) I would like to see this university become smoke-free; and (3) public places should be smoke-free, using a 5-point Likert scale as follows: strongly agree $=5$; agree $=4 ;$ neutral $=3$; disagree $=2$; and strongly disagree $=1$. Participants answered a question about existence of a policy against smoking in the university (Yes, no, and not sure) and only participants who answered yes proceeded to answer the following two questions: (1) what is the university policy against smoking; and (2) In your opinion, are the official policies about smoking in the university followed?

\section{Statistical Analysis}

We coded and analyzed all data using the Statistical Package for the Social Sciences version 24.0 (SPSS Inc, Armonk, New York City, USA). The total score for the knowledge of the smoking hazard was calculated using the methods described in Mansour. ${ }^{10}$ Total score of willingness to accept $\mathrm{SHS}$ exposure scale was calculated using the method described in Mansour and Bakhsh. ${ }^{30}$ We also calculated the total score for the support for a smoke-free policy after converting the 5-point Likert scale using the following codes: strongly agree $=5$ to +2 ; agree $=4$ to +1 ; neutral $=3$ to 0 ; disagree $=2$ to -1 ; and strongly disagree $=$ 1 to -2 by summing the score of the three items. The total score ranged from +6 (greater support) to -6 (No support).

For the categorical variables, we calculated the frequency and column percentages comparing smokers with nonsmokers using chi-square. For continuous variables, we calculated mean and standard deviation (SD), comparing smokers with nonsmokers using t-test. The alpha was set at 0.05 ; all tests were two-tailed.
Linear regression analyses assessed the support for a smoke-free policy. First, a series of simple linear regressions identified variables significantly related to the dependent variable - support for a smoke-free policy. The unadjusted regression coefficient $(\beta), 95 \% \mathrm{CI}$, p-value, and $\mathrm{R}^{2}$ were calculated for all independent variables. The explanatory variables were sex (men/women), smoking status (smokers/nonsmokers), total score for willingness to accept SHS exposure scale, the total score for knowledge of health hazards, awareness of policy existence (yes/no), having a smoker in the household (yes/no), having a smoker in friend's house (yes/no), and exposed to SHS in the university (yes/no).

Multiple linear regression analysis using a stepwise variable selection method was used when more than one variable was found to be statistically significant in the univariate analyses; by doing so, the relative contribution of each predictor variable could be obtained, while controlling for the influence of other variables. Any variable with a significance level of $p<0.25$ was used for multiple linear regression analysis. The adjusted $\beta$, $95 \% \mathrm{CI}$, and p-value for all independent variables were calculated.

\section{RESULTS}

Of 380 dental students invited to participate, 313 (82.4\%) returned complete questionnaires. Complete descriptive statistics of the categorical and continuous variables are displayed in (Table 1). Among our sample of dental students, $24 \%$ are smokers. The sample includes 57\% women, and $24 \%$ of the smokers are women. The subjects included in the sample reported that 39,25 , and $38 \%$ are exposed to SHS in the university, their household, and at their friends' houses respectively (Table 1). Also, we found that the average knowledge of smoking hazard score and the support for smoke-free policy score were higher among the nonsmokers than the smokers (20.87 vs 19.24 and 5.36 vs 2.23 respectively). Regarding the willingness to accept SHS exposure, we found that nonsmokers have a lower average score to accept SHS exposure than smokers (34.87 vs 57.21) (Table 1 ).

In all, $23 \%$ of the students reported that they smell smoke at the university. Also, $76 \%$ see cigarette filters on the ground at least sometimes, and 39\% reported that they are exposed to SHS at the university. Table 2 shows the awareness of the dental students about smoking policies at the university. When we asked about the awareness of the existing policy against smoking, $52 \%$ of smokers and nonsmokers knew that there is a policy against smoking. Among those who acknowledge the existence of a policy, only $64 \%$ know that it is prohibited to smoke anywhere on campus. Also, only $38 \%$ believe that this policy is followed or 
Table 1: Description of the 313 Saudi dental students who completed the survey

\begin{tabular}{llllr}
\hline Variables & & Nonsmokers, $N=239(76)$ & Smokers, $N=74(24)$ & $n$-value \\
\cline { 5 - 5 } Categorical & $n(\%)$ & $n(\%)$ & $18(24)$ & $<0.001^{*}$ \\
\hline Sex & $179(57)$ & $161(67)$ & $56(76)$ & $<0.001^{*}$ \\
Women & $134(43)$ & $78(33)$ & $40(54)$ & $0.002^{*}$ \\
Men & $121(39)$ & $81(33)$ & $25(34)$ & 0.053 \\
Exposed to SHS in the university (yes) & $79(25)$ & $54(22)$ & $33(45)$ & 0.161 \\
A smoker in the household (yes) & $118(38)$ & $85(35)$ & Mean \pm SD & $19.24 \pm 3.70$ \\
A smoker in a friend's house (yes) & & Mean \pm SD & $2.23 \pm 3.46$ & $<0.001^{*}$ \\
Continuous & & $20.87 \pm 2.88$ & $57.21 \pm 15.42$ & $<0.001^{*}$ \\
Knowledge of smoking hazard score & & $5.36 \pm 1.41$ & & $<0.001^{*}$ \\
Support for the smoke-free policy score & & $34.87 \pm 16.30$ &
\end{tabular}

${ }^{a}$ Chi-square test for frequencies and t-test for means; ${ }^{*} p<0.05$ (Significant)

Table 2: Awareness of the dental students about smoking policies in the university

\begin{tabular}{|c|c|c|c|c|}
\hline \multirow{2}{*}{ Characteristic } & & \multicolumn{2}{|c|}{ Smoking status } & \multirow[b]{2}{*}{$p$-value } \\
\hline & & $\begin{array}{l}\text { Nonsmokers } \\
N(\%)\end{array}$ & $\begin{array}{l}\text { Smokers } \\
N(\%)\end{array}$ & \\
\hline \multirow{3}{*}{$\begin{array}{l}\text { Do you know if the university has any policy } \\
\text { against smoking in the university? }(n=313)^{b}\end{array}$} & Yes, the university has a policy & $107(34)$ & $56(18)$ & \multirow[t]{3}{*}{$<0.001^{*}$} \\
\hline & No, the university does not have a policy & $27(9)$ & $8(3)$ & \\
\hline & Not sure if there is a policy & $105(34)$ & $10(3)$ & \\
\hline \multirow{4}{*}{$\begin{array}{l}\text { What is the university policy against } \\
\text { smoking? }(n=163)\end{array}$} & Smoking is prohibited anywhere on the campus & $58(36)$ & $45(28)$ & \multirow[t]{4}{*}{$0.004^{*}$} \\
\hline & $\begin{array}{l}\text { Smoking is prohibited only in the buildings } \\
\text { where classes are }\end{array}$ & $25(15)$ & $9(5)$ & \\
\hline & Smoking is only allowed in designated areas & $3(2)$ & $0(0)$ & \\
\hline & I do not know & $21(13)$ & $2(1)$ & \\
\hline \multirow{4}{*}{$\begin{array}{l}\text { In your opinion, are the official policies about } \\
\text { smoking in the university followed? }(n=163)\end{array}$} & Yes, they are followed & $44(27)$ & $18(11)$ & \multirow[t]{4}{*}{0.085} \\
\hline & No, the polices are not followed & $40(25)$ & $32(20)$ & \\
\hline & There are no official policies at the university & $1(1)$ & $0(0)$ & \\
\hline & I do not know & $22(13)$ & $6(3)$ & \\
\hline
\end{tabular}

${ }^{a}$ Chi-square test; ${ }^{b}$ Only participants who answered "Yes" proceeded to answer the following questions; * $p<0.05$ (Significant)

Table 3: Univariate analyses and multivariate analysis of the support for the smoke-free policy among Saudi dental students

\begin{tabular}{|c|c|c|c|c|c|}
\hline \multirow[b]{2}{*}{ Explanatory variables ${ }^{\mathrm{b}}$} & \multicolumn{3}{|c|}{ Univariate model } & \multicolumn{2}{|c|}{ Multivariate mode $^{a}$} \\
\hline & $\beta(95 \% \mathrm{Cl})$ & $p$-value & $R^{2}$ & $\beta(95 \% \mathrm{Cl})$ & $p$-value \\
\hline Sex (men) & $-1.69(-2.21 /-1.17)$ & $<0.001$ & 0.11 & $-0.49(-2.73$ to -0.58$)$ & 0.03 \\
\hline Smoking status (nonsmokers) & $3.13(2.59 / 3.68)$ & $<0.001$ & 0.29 & 1.95 (1.37 to 2.52$)$ & $<0.001$ \\
\hline Willing to accept SHS exposure score & $-0.06(-0.07 /-0.05)$ & $<0.001$ & 0.21 & $-0.02(-0.04$ to -0.01$)$ & $<0.001$ \\
\hline Knowledge of health hazard score & $0.37(0.29 / 0.45)$ & $<0.001$ & 0.22 & $0.26(0.20$ to 0.30$)$ & $<0.001$ \\
\hline Awareness of policy existence & $0.8(1.34 / 0.26)$ & $<0.004$ & 0.02 & $0.80(0.26$ to 1.34$)$ & 0.004 \\
\hline A smoker in the household (no) & $0.27(-0.36 / 0.91)$ & 0.39 & 0.002 & & \\
\hline A smoker in a friend's house (no) & $0.13(-0.44 / 0.70)$ & 0.69 & 0.001 & & \\
\hline Exposed to SHS in the university (no) & $0.61(0.05 / 1.17)$ & $<0.03$ & 0.061 & & \\
\hline
\end{tabular}

${ }^{a} p<0.0001, R^{2}=0.46$, adjusted $R^{2}=0.45$; ${ }^{b}$ The parameters of sex = women, smoking status $=$ smokers, a smoker in the household

$=$ Yes, a smoker in a friend's house $=$ Yes, and exposed to SHS in the university $=$ Yes were the reference categories

enforced, while $45 \%$ disagree and think that the policy is not followed.

\section{Determinants of Support for a Smoke-free Policy among Saudi Dental Students}

Univariate analysis (crude regression) results for the determinants of support for a smoke-free policy among Saudi dental students and unadjusted beta coefficients $(\beta)$ are shown in Table 3.
Sex, smoking status, willingness to accept SHS exposure, knowledge of health risks, awareness of policy existence, and exposure to SHS in the university were all statistically significant except for having a smoker in the household $\left(\beta=0.27, p<0.39, R^{2}=0.002\right)$ and having a smoker in a friend's house $\left(\beta=0.13, p<0.69, R^{2}=0.001\right)$.

The crude unadjusted regression models showed a direct relationship for increasing support for a smoke-free policy with being a nonsmoker $\left(\beta=3.13, p<0.0001, R^{2}=0.29\right)$, 
knowledge of health risk score $(\beta=0.37, \mathrm{p}<0.0001$, $\left.R^{2}=0.22\right)$, awareness of policy existence $(\beta=0.8, p<0.004$, $\left.R^{2}=0.02\right)$, and being exposed to SHS in the university $\left(\beta=0.61, p<0.03, R^{2}=0.06\right)$. However, being a man $\left(\beta=-1.69, p<0.0001, R^{2}=0.11\right)$ and willing to accept SHS exposure $\left(\beta=-0.06, p<0.0001, R^{2}=0.21\right)$ are inversely associated with support for a smoke-free policy. Examining the unadjusted models, we found that smoking status explained $29 \%$ of the support for a smoke-free policy.

We used a stepwise variable selection method to build a multivariate linear regression model. Collinearity analysis showed no sign of collinearity with all variance inflation factor reading below 10 ranging between 1 and 2. The presence of a smoker in the household and in a friend's house, awareness of policy existence, and exposure to SHS in the university were excluded from the multivariate model. This fitted model is statistically significant $\left(p<0.0001, R^{2}=0.46\right.$, adjusted $\left.R^{2}=0.45\right)$. The model explained $45 \%$ of the support for a smoke-free policy. The multivariate model showed greater support for a smokefree policy with being a nonsmoker $(\beta=1.95,95 \% \mathrm{CI}=$ $1.37-2.52, \mathrm{p}<0.0001)$, and higher knowledge of health risk score $(\beta=0.26,95 \% C I=0.20-0.30, p<0.0001)$. However, support for a smoke-free policy is inversely associated with being a man $(\beta=-0.49,95 \% \mathrm{CI}=-2.73$ to $-0.58, \mathrm{p}=$ 0.03 ) and increase in willingness to accept SHS exposure scale $(\beta=-0.02,95 \% \mathrm{CI}=-0.04$ to $-0.01, \mathrm{p}<0.0001)$.

\section{DISCUSSION}

Of the whole sample, $24 \%$ are smokers, and at least $25 \%$ are exposed to SHS in their homes, their friends' house, or at the university. Compared with smokers, nonsmokers have greater knowledge of the hazard associated with smoking, as well as greater support for a smoke-free policy. Also, smokers are more willing to accept SHS exposure than nonsmokers. Although there is a policy that bans smoking on the campus, only $52 \%$ of the students know that this policy exists. Of those who know that a policy exists, only $63 \%$ know that the policy bans smoking anywhere on campus, and $44 \%$ believe that the policy is not enforced or followed; $23 \%$ of the students reported smelling smoke on campus, $76 \%$ see cigarette filters, and $63 \%$ are exposed to SHS.

The model created here shows that being a man and the willingness to accept SHS exposure are associated with not supporting a smoke-free policy. On the contrary, being a nonsmoker and having better knowledge of the hazards of smoking are positively associated with support for a smoke-free policy. Using sex, smoking status, knowledge of smoking hazard score, and willing to accept SHS exposure score data, our model explains $45 \%$ of the variability in the support for a smoke-free policy.
Smokers account for $24 \%$ of the dental students, compared with $13 \%$ in a school in the capital of the country and in other places..$^{25,27,28}$ In our sample, women account for $24 \%$ and men for $76 \%$ of the smokers, which is similar to the distribution in other schools. . $^{25,27,28,31}$ In our study, we found that 25 to $39 \%$ of dental students are exposed to SHS either at their home, at their friends' houses, or at the university. This value is lower than has been reported in other studies, where they report that 60 to $90 \%$ are exposed to SHS. ${ }^{23,32}$

We found that $52 \%$ of the students knew that a policy exists about smoking on campus. However, only $64 \%$ know that the policy bans smoking anywhere on campus. Only 38\% think that this policy is followed or enforced. Other studies did not report awareness of the existence of a policy banning smoking.

In our study, we found that women, being a nonsmoker, having better knowledge of the smoking hazard, and being less lenient in accepting SHS exposure are all strong predictors of support for smoke-free policy on the university campus. Other studies in Saudi, New Zealand, Canada, and the USA reported similar results, where men and being a smoker present less support for the policy. ${ }^{23,27,28,31}$ On the contrary, no other studies examined the knowledge of the smoking hazards and the willingness to accept $\mathrm{SHS}$ as predictors of support for the smoke-free policy.

Our study has some limitations, including the small sample size and potential recall bias, self-reporting bias, and social desirability. The study was limited to dental students who might show some different characteristics with other faculties. We recommend a future study including a larger sample size, perhaps including the whole university and not focusing on the medical and dental student, thereby gaining a clearer image of the attitudes of the students across the university campus. The study has several strengths, one of which is the high response rate (82\%). Another strength is how this study evaluates the awareness and the support of the existing smoke-free policy.

\section{CONCLUSION}

We conclude that a policy banning smoking would be supported by those students who are knowledgeable about the health hazards of smoking and those who are unwilling to accept exposure to SHS. Students believe that, although the policy already exists, there is a need for better methods to enforce the policy on a wider scale.

\section{ACKNOWLEDGMENT}

The author extends his thanks and appreciation to Dr Ameerah Mansour for her help in data collection and editing. 
During this survey, the word smoke will refer to any type of tobacco smoke as that from cigarettes, moassel, shisha, cigar, pipe, or any other form of tobacco

\section{SMOKING STATUS QUESTIONS}

1. Which statement best describes your current smoking status?

If you have never smoked, please check the last box and skip to Question 9.

Current smoker

Occasional smoker

Ex-smoker (You used to smoke and quit smoking)

Nonsmoker

2. Which type or types of tobacco do/did you smoke? (Please check ALL that apply)

Cigarettes

Moassel.

Shisha

Others (please specify)

3. How many years have you been smoking or had you smoked?

D years

4. What was your age when you first started smoking?

W years

5. How frequently do you or did you smoke?

Cigarettes

Shisha.

Moassel.

Others (please specify)

\begin{tabular}{|c|c|c|c|c|}
\hline Daily & A few times a week & Once a week & A few times a month & Once a month \\
\hline$\square$ & $\square$ & $\square$ & $\square$ & $\square$ \\
\hline$\square$ & $\square$ & $\square$ & $\square$ & $\square$ \\
\hline$\square$ & $\square$ & $\square$ & $\square$ & $\square$ \\
\hline$\square$ & $\square$ & $\square$ & $\square$ & $\square$ \\
\hline
\end{tabular}

6. How many cigarettes and/or cigars do you or did you smoke at this university each day?

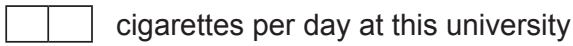

7. If you smoke at this university, where do you smoke? (Please select all that apply)

In stairwells or corridors

In student lounges.

In classrooms or lecture halls.

In restrooms

In university restaurants or cafeterias

Outside the buildings

Others (please specify)

8. How likely would you continue to smoke at this university if smoking was banned (prohibited)?
$\square$ Definitely will
$\square$ Probably will
$\square$ Might or might not
$\square$ Probably will not
Definitely will not

\section{QUESTIONS ABOUT EXPOSURE TO SECOND-HAND SMOKE}

Second-hand smoke is a smoke that comes from the use of a tobacco product (cigarettes, moassel, shisha, cigar, pipe, or any other form of tobacco) and smoke that is exhaled by smokers which anyone can be exposed to.

9. Where do you get exposed to second-hand smoke? (Please select ALL that apply)

I do not get exposed to second-hand smoke

In my home.

In the house of others

At the university

In restaurants/cafes

In public places

Others (please specify below)

10. How often do you smell tobacco smoke while you are at this university?
$\square$ Always
$\square$ Most of the time
$\square$ About half of the time
$\square$ Sometimes
$\square$ Never

11. How often do you see cigarette filters on the ground while you are at this university?
$\square$ Always
$\square$ Most of the time
$\square$ About half of the time
$\square$ Sometimes
$\square$ Never 
12. How frequently are you exposed to second-hand smoke at the university?
$\square$ Always
$\square$ Most of the time
$\square$ About half of the time
$\square$ Sometimes
$\square$ Never

13. How much do you think a smoking ban (prohibiting smoking) at this university would affect your academic performance?
$\square$ A great deal
$\square$ A lot
$\square$ A moderate amount
$\square$ A little
$\square$ Not at all

14. How much do you agree with the following statements?

A university should be a smoke-free environment.

I would like to see this university become smoke-free.

A smoking ban would be unfair to smokers.

Smoking is dangerous to smokers' health.

A smoke-free policy is difficult to enforce.

Smoking policy is effectively enforced at this university.

A smoke-free campus will help a smoker quit.

Tobacco smoke is dangerous for nonsmokers' health.

Children who are exposed to tobacco smoke have more illnesses, such as colds.

Exposure to tobacco smoke can cause lung cancer in nonsmokers.

Public places should be smoke free.

Parents or adults should not smoke near children.

Smoke from other people's cigarettes will shorten my life.

Designated areas for smoking should be assigned in the university.

\begin{tabular}{lllll}
\hline $\begin{array}{l}\text { Strongly } \\
\text { agree }\end{array}$ & Agree & Neutral & Disagree & $\begin{array}{l}\text { Strongly } \\
\text { disagree }\end{array}$ \\
\hline$\square$ & $\square$ & $\square$ & $\square$ & $\square$ \\
$\square$ & $\square$ & $\square$ & $\square$ & $\square$ \\
$\square$ & $\square$ & $\square$ & $\square$ & $\square$ \\
$\square$ & $\square$ & $\square$ & $\square$ & $\square$ \\
$\square$ & $\square$ & $\square$ & $\square$ & $\square$ \\
$\square$ & $\square$ & $\square$ & $\square$ & $\square$ \\
$\square$ & $\square$ & $\square$ & $\square$ & $\square$ \\
$\square$ & $\square$ & $\square$ & $\square$ & $\square$ \\
$\square$ & $\square$ & $\square$ & $\square$ & $\square$ \\
$\square$ & $\square$ & $\square$ & $\square$ & $\square$ \\
$\square$ & $\square$ & $\square$ & $\square$ & $\square$ \\
$\square$ & $\square$ & $\square$ & $\square$ & $\square$ \\
$\square$ & $\square$ & $\square$ & $\square$ & $\square$ \\
$\square$ & $\square$ & $\square$ & $\square$ & $\square$
\end{tabular}

15. How often do you do each of the following?

When I go to an outdoor event where cigarette smoking is present,

\begin{tabular}{lllll}
\hline Always & $\begin{array}{l}\text { Most of } \\
\text { the time }\end{array}$ & $\begin{array}{l}\text { About half } \\
\text { of the time }\end{array}$ & Sometimes & Never \\
\hline$\square$ & $\square$ & $\square$ & $\square$ & $\square$
\end{tabular}

I will move away to avoid it.

When I go to an outdoor event where water pipe smoking is present,

I will move away to avoid it.

When exposed to second-hand smoke, I wash my clothes solely

to remove the smell of smoke from them even if they are otherwise clean.

I routinely sit with people who smoke shisha.

I routinely sit with people who smoke Moassel.

I routinely sit with people who smoke cigarettes.

I find second-hand smoke offensive.

When I encounter someone who is smoking, I distance myself to make sure that I will not be exposed to smoke.

If I am with a group of people, and someone begins to smoke, I will remain with the group.

If I encounter a friend or relative who is smoking, I will sit and talk with him/her while he/she is smoking.

When I am in a public place, such as a restaurant or office, I will leave if unable to sit in the nonsmoking section.

If my husband/wife, friends, or relatives are gathering in a designated smoking area to smoke, I will join them rather than be alone.

If I am with people who are smoking and I cannot leave, I will ask them to stop smoking.

I will sit in the smoking section of a public place, if there are no seats available elsewhere.

When I travel by car, I ask the driver or others not to smoke inside the car.

16. Do you know if the university has any policy against smoking in the buildings?

Yes, the university has a policy.....

No, the university does not have a policy.............

Go to question \# 19

Not sure if there is a policy

$\square$ Go to question \# 19 
17. What is the university policy against smoking?

Smoking is prohibited anywhere on the campus

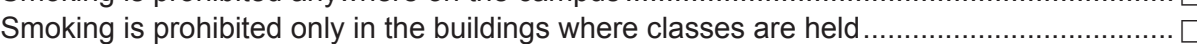

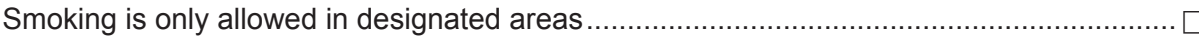

I do not know

18. In your opinion, are the official policies about smoking in the buildings followed?

Yes, they are followed.

No, the polices are not followed.....

There are no official policies at the university.....

I do not know

19. Where do you see people smoke at the university?

In offices....

In stairwells or corridors

In lounges or student areas

In classrooms or lecture halls

In restrooms

In university restaurants or cafeterias

Outside the buildings

\section{BACKGROUND QUESTIONS}

20. GENDER:

Male.

Female.

21. In which year were you born?

22. In what year of school are you currently enrolled?

Fourth

Fifth......

Sixth.

Intern

Resident

23. What was your academic performance last year?

Excellent $(A)$....

Very good $(B)$

Good (C).

Fair (D) .

Poor (F)

Kindly write down any further comments, or suggestions you have.

Thank you for completing this survey

\section{REFERENCES}

1. World Health Organisation. The role of health professionals in tobacco control. Geneva: WHO; 2005. Available from: http:/ / www.who.int/tobacco/resources/publications/wntd/2005/ bookletfinal_20april.pdf.

2. Mecklenburg RE. Tobacco prevention and control in dental practice: the future. J Dent Educ 2001 Apr;65(4):375-384.

3. Shaik SS, Doshi D, Bandari SR, Madupu PR, Kulkarni S. Tobacco use cessation and prevention-a review. J Clin Diagn Res 2016 May;10(5):ZE13-ZE17.
4. Sood P, Narang R, Swathi V, Mittal L, Jha K, Gupta A. Dental patient's knowledge and perceptions about the effects of smoking and role of dentists in smoking cessation activities. Eur J Dent 2014 Apr;8(2):216-223.

5. Siddiqui S, Ogbeide DO. Profile of smoking amongst health staff in a primary care unit at a general hospital in Riyadh, Saudi Arabia. Saudi Med J 2001 Dec;22(12):1101-1104.

6. Behbehani NN, Hamadeh RR, Macklai NS. Knowledge of and attitudes towards tobacco control among smoking and non-smoking physicians in 2 gulf arab states. Saudi Med J 2004 May;25(5):585-591. 
7. Smith DR, Zhao I, Wang L. Tobacco smoking among doctors in mainland China: a study from Shandong province and review of the literature. Tob Induc Dis 2012 Sep;10(1):14.

8. Warren CW, Sinha DN, Lee J, Lea V, Jones NR. Tobacco use, exposure to secondhand smoke, and cessation counseling among medical students: cross-country data from the Global Health Professions Student Survey (GHPSS), 2005-2008. BMC Public Health 2011 Feb;11:72.

9. Warren CW, Sinha DN, Lee J, Lea V, Jones N, Asma S. Tobacco use, exposure to secondhand smoke, and cessation counseling training of dental students around the world. J Dent Educ 2011 Mar;75(3):385-405.

10. Mansour AY. Predictors of smoking among Saudi dental students in Jeddah. Am J Health Behav 2017 May;41(3):329-337.

11. Al-Turki YA. Smoking habits among medical students in Central Saudi Arabia. Saudi Med J 2006 May;27(5):700-703.

12. Al-Haqwi AI, Tamim H, Asery A. Knowledge, attitude and practice of tobacco smoking by medical students in Riyadh, Saudi Arabia. Ann Thorac Med 2010 Jul-Sep;5(3):145-148.

13. Bassiony MM. Smoking in Saudi Arabia. Saudi Med J 2009 Jul;30(7):876-881.

14. Wali SO. Smoking habits among medical students in western Saudi Arabia. Saudi Med J 2011 Aug;32(8):843-848.

15. Ministry of Health/WHO. WHO STEPwise approach to NCD surveillance: country-specific STANDARD REPORT, Saudi Arabia. Saudi Arabia: MoH/WHO; 2005. Available from: http://www.who.int/chp/steps/2005_SaudiArabia_ STEPS_Report_EN.pdf.

16. Jarallah JS, al-Rubeaan KA, al-Nuaim AR, al-Ruhaily AA, Kalantan KA. Prevalence and determinants of smoking in three regions of Saudi Arabia. Tob Control 1999 Spring;8(1):53-56.

17. Moradi-Lakeh M, El Bcheraoui C, Tuffaha M, Daoud F, Al Saeedi M, Basulaiman M, Memish ZA, AlMazroa MA, Al Rabeeah AA, Mokdad AH. Tobacco consumption in the Kingdom of Saudi Arabia, 2013: findings from a national survey. BMC Public Health 2015 Jul;15:611.

18. Al-Khashan HI, Al Sabaan FS, Al Nasser HS, Al Buraidi AA, Al Awad AD, Horaib GB, Al Obaikan AH, Mishriky AM. The prevalence of smoking and its associated factors among military personnel in Kingdom of Saudi Arabia: a national study. J Family Community Med 2014 Sep;21(3):147-153.

19. Chung-Hall J, Craig L, Gravely S, Sansone N, Fong GT. Impact of the WHO framework convention on tobacco control on the implementation and effectiveness of tobacco control measures : a global evidence review. Waterloo: University of Waterloo; 2016.

20. University KA. Pages-sprules @ studentaffairs.kau.edu.sa. Available from: https://studentaffairs.kau.edu.sa/Pagessprules.aspx.
21. AlSwuailem AS, AlShehri MK, Al-Sadhan S. Smoking among dental students at King Saud University: consumption patterns and risk factors. Saudi Dent J 2014 Jul;26(3):88-95.

22. Martínez C, Méndez C, Sánchez M, Martínez-Sánchez JM. Attitudes of students of a health sciences university towards the extension of smoke-free policies at the university campuses of Barcelona (Spain). Gac Sanit 2017 Mar-Apr;31(2): 132-138.

23. Braverman MT, Hoogesteger LA, Johnson JA. Predictors of support among students, faculty and staff for a smoke-free university campus. Prev Med 2015 Feb;71:114-120.

24. Fallin A, Roditis M, Glantz SA. Association of campus tobacco policies with secondhand smoke exposure, intention to smoke on campus, and attitudes about outdoor smoking restrictions. Am J Public Health 2015 Jun;105(6):1098-1100.

25. Andreeva TI, Ananjeva GA, Daminova NA, Leontieva TV, Khakimova LK. Smoke-free universities help students avoid establishing smoking by means of facilitating quitting. Heal Promot Perspect 2016 Jan;5(4):241-249.

26. Bich NN, Cook M, Johnstone K, Capra M, Lan VT. Students' knowledge and attitudes towards smoke-free universities: changes since enactment of Vietnamese Tobacco Control Legislation. Asian Pac J Cancer Prev 2016 Apr;17(S1): 65-70.

27. Almutairi KM. Attitudes of students and employees towards the implementation of a totally smoke free university campus policy at King Saud University in Saudi Arabia: a cross sectional baseline study on smoking behavior following the implementation of policy. J Community Health 2014 Oct;39(5):894-900.

28. Marsh L, Robertson LA, Cameron C. Attitudes towards smokefree campus policies in New Zealand. N Z Med J 2014 May;127(1393):87-98.

29. Gharaibeh H,Haddad L, Alzyoud S, El-Shahawy O, Baker NA, Umlauf M. Knowledge, attitudes, and behavior in avoiding secondhand smoke exposure among non-smoking employed women with higher education in Jordan. Int J Environ Res Public Health 2011 Nov;8(11):4207-4219.

30. Mansour AY, Bakhsh Z. Measuring willingness to accept second-hand smoke exposure. Am J Health Behav 2015 Nov;39(6):849-855.

31. Procter-Scherdtel A, Collins D. Social norms and smoking bans on campus: interactions in the Canadian university context. Health Educ Res 2013 Feb;28(1):101-112.

32. Aslam SK, Mehboob B, Zaheer S, Shafique K. Awareness and support for anti-tobacco policies among health professional students in Pakistan: findings from the Global Health Professional Students Survey, 2011. Subst Abuse Treat Prev Policy 2015 Mar;10:7. 